\title{
WeChat: Social Network and Smart City
}

\author{
Jing Zhang ${ }^{1}$, Cristobal Fernandez Muñoz ${ }^{1} \&$ Liisa Irene Hänninen ${ }^{1}$ \\ ${ }^{1}$ Faculty of Information Science, Complutense University, Madrid, Spain \\ Correspondence: Jing Zhang, Complutense University, Av. Complutense, 3. 28040 Madrid, Spain. E-mail: \\ jingzh02@ucm.es
}

Received: August 14, 2019; Accepted: August 27, 2019; Published: September 2, 2019

\begin{abstract}
The work focuses on the study of WeChat (main social network in China) and its digital activity for its advanced functionalities which build intelligent society in China. The importance of this platform lies in the prohibition of Western social networks in China. For 7 years, WeChat has evolved as a "super social network", from an instant messaging application to a hybrid including application, marketplace, payment method and operating systemz, as an integrated means rather than just social network. In today's western world, almost no network can be compared with WeChat in terms of its functionalities. It is a good example of promotion and development of the intelligent society because of its advanced functionalities. The new usage and the rapid expansion of its integrated functionality and impacts form the new communication consumption framework in China. This work shows how an intelligent society changes and develops through a social network, and detailed analysis of advanced technology and social network of WeChat to give a good example to Westren countries which want to build intelligent society.
\end{abstract}

Keyword: social network, WeChat, smart society, technical innovation

\section{Introduction}

It was the rapid growth of the Internet of Things that gave birth to the "smart city", a new concept in urban life that is developing alongside the use of hardware related to city infrastructure and intelligent software. Just Smart City stands for the improvement on by means of integrating intelligent technologies such as "sustainable tools and solutions in innovation, the Internet of Things, Big Data, digital platforms and, ultimately, data and Information" (Ontiveros, Vizcaíno, and Sabater, 2016) under different types of urban settings, for the purpose of higher efficiency of the city.

In the McKinsey report 2018, the article "Smart city: digital technology to create a livable home" indicated that several Chinese cities have advanced in their overall urban structures. According to this report, it is feasible to summarize that the technical base of this type of cities is the considerable level of facilities which is reflected in the high penetration rate of smartphones, the promotion of smart meters and the effective smart monitoring coverage. For instances, Shanghai and Hong Kong are the forerunners regarding the scale of their data platforms, while Shenzhen is one of the best cities in the world for wireless Internet coverage (pp. 10-14).

Moreover, great popularity of smartphone use, high rate of wireless Internet coverage, and easy access to new application technologies of the residents have jointly guaranteed a well-conditioned environment for the growth of social network, in which citizens use smart applications to build a life governed by new standards, and further, the social network will facilitate the development of smart city. In particular, WeChat, the most widely used Internet social platform in China, is taken as an example to show how social networks provide intelligent public services. WeChat can be considered as a super social network, as a useful and effective product to combine online and offline communications (real-life communication). The boundaries between virtual social networks and real social networks gradually fade and even close to their disappearance. WeChat has become a social and economic phenomenon.

\section{Methodology}

\subsection{Reference Review}

For the literature review, detailed research and knowledge on related reports and books were carried out. From theoretical knowledge, it involves a series of related knowledge points, such as social networks, network society, smart city and mobile ecosystem etc. 


\subsection{Case Study}

To show the influence and expansion of social networks in China in smart cities, WeChat is taken as the object of investigation. The main method is to study the functionalities of WeChat. Through the practical experience of the application functionalities, we summarize the application of Chinese social network in the aspect of transport and life services. The specific investigated functionality focuses mainly on the practices of the two main aspects:

1. Digital payment

2. Social network services that are not message functionality

\subsection{Objective}

Display the application of social networks in the construction of smart cities,analyze what kind of impact and social structure has developed as a result of the application, and Present the specific case of smart city in China through the analysis of WeChat.

\section{Specific Objectives}

1. Introduce WeChat and its innovative features embedded in it. Mainly Mini programs and instant digital pay.

2. Explain the contribution of social networks to the development of smart city in China through analyzing WeChat from various aspects of the economic activity on it.

3. Offer inspiration to other countries and other social networks.

\section{Theoretical Framework}

\subsection{The Network Society and Interactive Digital Communication}

The use of the network reflects the development and digital structure of society. In the technological evolution, the form of media and services, and new deposit supports are constantly promoted, which constitute the new functionalities and innovative forms of information consumption. Wifi is the Internet support for portable deposits of digital activities, it powerfully provides the Internet access to the users and the use of Internet advances the portable deposits, for example, the smartphones. Due to its Internet coverage for a large public area, Wifi offers an effective support to the connection between digital functionalities, which implies a new consumption behavior through the virtual world (Government of Navarra, Acércate).

\subsection{Smart City}

The smart city is a new social structure generated by the interaction among citizens on the Internet, supported by cyber technology. The elementary characteristics of this type of city is that technological advances are used to solve the daily demands of residents which makes the way of life increasingly digital and innovative (Marieta del Rivero, 2019). From a virtual point of view, the Internet social structure offers an interactive participation as the reality of everyday life does. The internet activities carried out by the citizens in this virtual societyextensively expand the structure and the space of life, which is a circumstance that also clearly defines the term "smart city". The behavior related to the interactive communication in the digital city may have several forms and multiple activities since users can Internet to get and transmit information through the Internet, which means new consumption of real-life activities.

The activities in real life subject to a smart city environment are multiple, from the online viewing of news in the form of text, image, or video, to acquiring mobile services, participation in social networks, mobile online payment and many others functionalities performed through smartphones connected to the Internet. New forms of social relations and lifestyle patterns have affected consumption behavior.

\subsection{Web 2.0 and Social Networks 2.0}

Web 2.0, society 2.0 and social networks 2.0. The reason for them being versioned 2.0 is they suggest important variations for the structure of contemporary life. Web 2.0 is characterized as "the social phenomenon based on the interaction of different user-centered web applications that facilitate the exchange of information, collaboration and multimedia interactivity in real time" (Muñoz, 2012, p. 69). With the help of Web 2.0, social networks become more exciting and heterogeneous. Web 2.0 results from a new method to develop the websites that makes an innovative use of the Word Wide Web. The products of Web 2.0 such as blogs, pages bring together various services, social networks, etc.

The interactivity of web 2.0 is exhibited ubiquitously on the Internet. As a reflection of Web 2.0, social networks inform the user of new trends and more functions. One could highlight interesting interactivities such as: chat, 
email, digital space, search engine, subscription, online payment, etc. Then, what is the diffenrence between Social networks 2.0 social networks 1.0 ? The real revolution of the version 2.0 is that new technologies and innovations are incorporated into social platforms as iconic as Facebook, Twitter or Instagram, and WeChat. The relationship between the technical innovation of Web 2.0 and social networks significantly enriches these platforms.

\subsection{Mobile Internet and Mobile Ecosistema}

Mobile Internet has benefited from the maturity of high-speed digital communication networks, and is providing new services to consumers such as applications. Smartphones have become the most popular device for users to access the Internet with the use of data and Wifi. They play an important role in the media use, highlights the new use and consumption of this tool and formulate a new mobile ecosystem. GSMA (2017) has described the use of smart mobile as "a thriving ecosystem" that influences the growing development of the mobile ecosystem. The smart mobile start to serve as the building blocks of social networks, since this ecosystem provides another manner for the creation, edition and dissemination of services in the new form of citizen consumption, such as recent payment methods or mobile entertainment, which causes the emergence of a new consumption model, thus configuring the current behavior in the urban environment.

\section{WeChat and Smart City}

\subsection{Payment Methods and Mini Programs}

WeChat is the most popular social platform now in mainland China, is considered a "super social network" for its integration of various functionalities. In 2010 WeChat was released by Tencent, one of the largest Chinese Internet company previously announced in China, that created its first social platform named QQ circa 2000.

The main function of WeChat in its formation was instant messaging, similar to WhatsApp. As it continues to develop to the present, WeChat can be considered an excellent combination of the most popular international social networks, in another word, "WeChat is an application of applications" (Tamara, Fanego, 2016). In it we appreciate the integrated and even improved functions of WhatsApp, Facebook, Instagram, Skype, etc. At anytime the technology update influence these social networks it changes Wechat as well. Its characteristics are those of an application that meets the following functions:

\section{- Payment Methods}

WeChat Pay functionality has become the main service of instant and cashless payment in China (Tencent, Ipsos and RDCY, 2017) with the support of a digital bank in WeChat called "WeChat Wallet" launched in 2013. Payment with the wallet allows the users to pay for goods and services by the credit card associated with WeChat plus identity verification. Subsequently, you can check the payments made in the "WeChat Payments" function. Apart from functioning as if a real bank, it also allows you to make transfers in the message interface, or receive money in "WeChat Wallet". With this functionality, WeChat becomes the first social platform that makes digital payments in messages, a system that is being extended by Chinese society with a high frequency of use, both at the consumer level and at the establishment level: from individual to large company they accept WeChat payments.

However, payments through "WeChat wallet" are different from digital payments with a bank card, since such functionality does not depend on any bank; However, users are allowed to transfer money into Wechat from a bank, so this function could be considered an advanced version of PayPal. In this way, WeChat has established itself as the most used social network with a greater commercial value than its competitors, given that it has managed to bring up a new consumption behavior for the vast majority of Chinese citizens.

\section{- Mini Programs}

Tencent News claimed in 2016 that WeChat would unveil an important new technology: a lightweight software called Mini programs. Mini programs is an application that can be used without downloading and installing. Mini programs ensure that the information is always at your fingertips, that is, allow third-party applications to be used in WeChat without installing the software. These applications are available to a WeChat users once he/she is located. It is of great convenience to circumvent the excessive application downloads on our device, since they will be ready to use from their place of origin. (Tencent Technology, 2016). According to Tencent's report for the fourth quarter of 2017, the Wechat applet has more than 170 million active accounts every day (Wen, Wang, 2018).

\subsection{Specific Case}

\subsubsection{Electronic Consumption}

The most intuitive experience in a smart city is the great dissemination and deep penetration of mobile payments. In fact, the "Smart Life Solution" takes advantage of the digital payment functionality offered by WeChat, thanks 
to its great expansion in China. Given that it has currently covered almost all national industries WeChat pursues to provide greater comfort to the public in most of the everyday matters that include economy activities, transportation, health, government procedures, etc.

From the economic aspect, the WeChat Pay performs not only a series of digital transaction processes such as payments, receipt of payments, transfer, billing, etc., but also introduces a two-dimensional scanner. The scanner yields a novel scanning behavior that absolutely eliminating the use of paper and extra electronic devices (or components). Regarding government procedures, "WeChat purse" in WeChat Pay is authorized as an official access to the social insurance payment and other events like checking the balance of the public housing welfare fund.

WeChat Pay is also combined with mini Programs to be used in e-commerce, which facilitates everyday matters both offline and online. In WeChat Pay there is a sub-functionality named "red envelope", an Chinese custom of giving monetary gift. WeChat friends can exchange digital money through messages using this "envelope". Currently, merchant who operate a mini program give away "red envelopes" with small amount of digital money to bring the attention of consumers. This digital money can be seen directly by users in their "WeChat Wallet". This interesting promotion strategy activates interaction between consumers and merchants.

\subsubsection{Public Transport System}

WeChat provides a variety of feasible optimizations to the public services through its subsidiary functions, small programs and payment methods.

WeChat multi-application function allows the following services to make use of digital payment:

Tabla 1. The services to make use of digital payment

\begin{tabular}{lll}
\hline $\begin{array}{l}\text { Public service in the social } \\
\text { network }\end{array}$ & $\begin{array}{l}\text { Mini programs } \\
\text { Several Apps inserted in } \\
\text { WeChat }\end{array}$ & $\begin{array}{l}\text { It combines WeChat user data and efficient reach } \\
\text { to provide more personalized services. }\end{array}$ \\
\hline Bicycle-sharing system & $\begin{array}{l}\text { Use WeChat payment } \\
\text { methods to pay in digital } \\
\text { money. }\end{array}$ & $\begin{array}{l}\text { Increase the flow of funds, develop a concept of } \\
\text { environment. }\end{array}$
\end{tabular}

Call a car service with WeChat, Use WeChat payment Increase the flow of funds, develop a concept of new payment method for this methods to pay in digital green travel, more sustainable for the urban service money. environment.

QR code to pay, QR code QR code scanning Increase the flow of funds, develop a concept of electronic bus card green travel, more sustainable for the urban environment.

Vehicle service: traffic violation / fuel loading / parking / car accidents

Transportation: congestion consultation / long-distance bus ticket / indoor road recommendation / public exchange / taxi / public bicycle / water on the road

Source: self- made.

\subsubsection{Smart Community}

- The Shared Economy

In 2012, shared electronic transport emerged in the Chinese market. "the main services include car rental, car sharing, driving, taxis, shared bicycles and other shared travel services to become general services"(iResearch.2017, p.6). Due to this type of service, people can travel without having to own a vehicle (bicycle, car, etc.).Other than vehicle share, Bicycle-sharing system has been available only since two years ago. In this biennium, the shared bicycle industry has experienced explosive growth. "The number of shared bicycle users will reach 235 million in 2018” (IiMedia Research, 2018, p.8). We noticed that Shared bicycles have become a means of daily transportation for urban residents rather than mere weekend entertainment. 
In the big cities of China, shared bicycles can be seen in any corner of the street. Users can unlock bicycles through their mobile phones and ride them wherever they are. In the Chinese market, competition between bike sharing companies is fierce. According to iiMedia Research data, there are more than 10 companies of that kind in China, among which the leading brands are ofo and Mobike (IiMedia Research. 2018).

- WeChat Smart Activity

In "WeChat Wallet" you can find an entry called "public service", which offers digital access to various public services which are listed here:

Tabla 2. Public servic in WeChat

Medicine service: Vaccine service / Emergency service / Medical service / Registered doctors

Insurance service: check the social security information

Meteorological and environmental protection: protection against meteorological variations and environmental risks

Government services: Complaints / Taxes / Education / Industry / Civil matters / Court / Notary

Government services: Complaints / Taxes / Education / Industry / Civil matters / Court / Notary

Source: self- made.

These services effectively suffice daily needs, and link the government, commerce, residents and properties together to create a comfortable and convenient community, intelligent access control, online payment, fast delivery and efficient operation in many areas.

\section{Conclusion}

The innovation of the social platform WeChat has helped improve the information technology and services of the city thanks to the advantages of cloud calculations, large databases, artificial intelligence, etc. In particular, WeChat payment has changed the way of life in the cities of China, and facilitated the development of Smart City. WeChat is a good example of integrated social network, it is a successful product of society 2.0, This social network is different from other traditional social networks that only focus on one or a few more specific uses, WeChat breaks the definition of social network that only serves to make communications, and their functions and objectives far exceed those of other social networks. Smart city focuses on processing the information of everyday need, service, exchange and synergy, which is decentralized and fragmented. WeChat have integrated the information into an organic entity. with the better involvement of elements and strong regulatory capacity, which leading a great advance in urban computerization that continuously improve the quality of life of residents.

\section{References}

Del Rivero, Marieta. (2019). Smart Cities. Spain: Lid.

Fanego, I., \& Tamara, L. (2016). Cómo WeChat va a cambiar el mundo. España: 2geeks1city, 6.[PowerPoint slides]. Retrieved from https://www.2geeks1 city.com/ebooks/WeChat_Guia_Completa_2geeks1city.pdf

Gobierno de Navarra, Acércate @ Las TIC. (Sin fecha). Uso de dispositivos móviles (teléfonos móviles, smartphones, ebbok, Gps y Tablet). Spain: Dirección General de Politica Económica y Empresarial. [PowerPoint slides]. Retrieved from https://www.navarra.es/NR/rdonlyres/48F9746B-080C-4DEA-BD95A5B6E01797E1/315641/7Usodedispositivosmoviles.pdf

GSMA. (2017). Smartphones impulsan el crecimiento del ecosistema móvil latinoamericano. Mobile World Congress Americas. [PowerPoint slides]. Retrieved from https:/www.gsma.com/newsroom/wpcontent/uploads/110917_MWCA_LatAm_v3_SPA_final.pdf

IiMedia Research. (2018). Monitoring report of China's shared bicycle industry for the first half of 2018. China: iimedia, 8 .

IResearch. (2017). China shared the research report of the bicycle industry. China: IResearch Institute, 6. [PowerPoint slides]. Retrieved from http://report.idx365.com/艾瑞/2017 年中国共享单车行业研究报 告.pdf 
McKinsey Global Instituto. (Junio de 2018). Smart Cities: Digital Solutiones for a more liveable future. McKinsey \& $\quad$ Company, $\quad$ 10-14. $\quad$ [PowerPoint $\quad$ slides]. $\quad$ Retrieved from https:/www.mckinsey.com/ /media/mckinsey/industries/capital\%20projects\%20and\%20infrastructure/our $\% 20$ insights/smart $\% 20$ cities $\% 20$ digital $\% 20$ solutions $\% 20$ for $\% 20 \mathrm{a} \% 20$ more $\% 201$ ivable $\% 20$ future/mgismart-cities-full-report.ashx

Muñoz, C. F. (2012). Las Relaciones Públicas ante el reto digital y el fenómeno Twitter: estudio sobre la respuesta de las agencias de RR.PP. y del subsector empresarial de las bebidas fermentadas en España. Spain: Universidad Complutense de Madrid. [PowerPoint slides]. Retrieved from https://eprints.ucm.es/16169/1/T33833.pdf

Ontiveros, E., Vizcaíno, D., \& Sabater, V. L. (2016). Las ciudades del futuro: inteligentes, digitales y sostenibles. Spain:Ariel; Telefonica Fundación. [PowerPoint slides]. Retrieved from https:/www.google.com/search?client=safari\&rls=en\&q=Las+ciudades+del+futuro:+inteligentes, +digitales $+\mathrm{y}+$ sostenibles.\&ie $=\mathrm{UTF}-8 \& \mathrm{oe}=\mathrm{UTF}-8$

Tencent, Ipsos. (2017). Smart Life: A Cashless Reality. Chongyang Institute for Financial Studies at Renmin University of China; Ipsos.

Wen, H., \& Wang, C. (2018). Tencent in-depth research. China: TF Securities.

\section{Copyrights}

Copyright for this article is retained by the author(s), with first publication rights granted to the journal.

This is an open-access article distributed under the terms and conditions of the Creative Commons Attribution license (http://creativecommons.org/licenses/by/4.0/). 